\title{
The Effects Of Hindsight Bias On Experienced And Inexperienced Auditors' Relevance Ratings Of Adverse Factors Versus Mitigating Factors
}

\author{
Kim L. Anderson, Indiana University of Pennsylvania, USA
}

\begin{abstract}
Hindsight bias is the tendency for individuals who have been provided with the outcome of an uncertain event to systematically overstate their abilities to have predicted that outcome in foresight. Individuals also rate cues supporting this known outcome as more relevant than the cues supporting alternative outcomes. In an experiment using the case data of a troubled company, the current study explores the effects of outcome information on both experienced and inexperienced auditors' going-concern judgments (i.e., whether or not they believed the company would succeed or fail within one year) and the extent to which the outcome information influences the auditors' relevance ratings of the case cues and whether this effect is greater for experienced auditors as compared to inexperienced auditors. The current study predicts that in this task, auditors' implicit knowledge of the differential costs associated with alternative audit decision errors, coupled with the nature of auditor training, will influence their cognitive processing, leading to results that differ from prior psychological studies in a systematic manner.

Specifically, the current study predicted and found that despite the outcome information provided, both experienced and inexperienced auditors rated failure cues (i.e., adverse factors) as more relevant than success cues (i.e., mitigating factors); the effect was not greater for experienced auditors. However, the current study also predicted and found that due to hindsight bias, auditors, who are provided with the failure outcome, were more likely to rate the adverse factors as more relevant than the mitigating factors than did the auditors who were not provided with outcome information.
\end{abstract}

Keywords: Hindsight Bias; Going-Concern Judgments; Cue Relevance Ratings

\section{INTRODUCTION}

\footnotetext{
C ndividuals who have been provided with the outcome of an uncertain event tend to systematically overstate their abilities to have predicted that outcome in foresight; this phenomenon is known as hindsight bias. They also rate the cues supporting the reported outcome as more relevant than the cues supporting non-reported outcomes. Further, they deny that knowledge of the event's actual outcome has affected their predictions or their cue ratings. Hindsight bias has been found to influence several audit judgments, including internal control evaluations (Reimers \& Butler, 1992), audit opinion decisions (Reimers \& Butler, 1992), preliminary analytical review judgments (McDaniel \& Killney, 1994; Kennedy, 1995), and going concern judgments (Kennedy, 1995; Anderson, 2000).
} 
In an experiment involving both experienced and inexperienced auditors, this paper investigates the effects of outcome information and experience on auditors' going-concern judgments and on their cue relevance ratings. In past psychological studies (Fischhoff, 1975; Wasserman, Lempert, \& Hastie, 1991), it was found that subjects informed of the outcome of an uncertain event (when compared to control subjects who were not informed of the actual outcome) rated cues supporting the given outcome as more relevant than the cues supporting non-reported outcomes. Prior auditing studies, using a going-concern task (Buchman, 1985; Maddocks, 1989), have not been successful in replicating these cue relevance results despite the fact that auditors have been found to be prone to hindsight bias.

However, these prior auditing studies did not take into consideration the fact that the psychological studies they were attempting to replicate used student subjects performing simplified tasks, whereas their studies involved accountants performing a real-world task. Due to the differential costs of alternative audit decision errors, coupled with the unique nature of auditor training, auditors' cue relevance ratings are likely to differ from those of students in a systematic way. Specifically, because auditors know that failing to uncover negative information or "adverse factors" (i.e., cues pointing toward bankruptcy) poses far more dire consequences to an auditing firm than does failing to uncover positive information or "mitigating factors" (i.e., cues pointing toward continued success), they cognitively attend to adverse factors more closely and are likely to view adverse factors as more relevant. In addition, auditors are trained and required by professional standards (Statement on Auditing Standards No. 59, AICPA, 1988) to first identify and evaluate adverse factors when auditing companies with going-concern problems and to only search for mitigating factors if the adverse factors create "substantial doubt" about the company's ability to continue. This training would also likely cause auditors to view adverse factors as more relevant.

As a result, the current study predicted and found that despite the outcome information provided, all auditors rate adverse factors as more relevant than the mitigating factors. This is a case where the nature of the auditing task supersedes the effects of hindsight bias. However, the current study also predicted and found that due to the presence of hindsight bias, auditors informed that the case company failed rate the adverse factors as more relevant than the mitigating factors to a greater extent than do auditors not provided with outcome information. The results of this study illustrate the importance of exercising caution when importing the results from psychological studies using student subjects and simplified tasks to an auditing domain using experienced subjects and real-world tasks.

The remainder of the paper is organized as follows. The following section presents the theory and hypotheses development. The methodology used to test the hypotheses is next, followed by the results section. The paper's implications are summarized and discussed in the final section.

\section{THEORY \& HYPOTHESES DEVELOPMENT}

\section{Presence of Hindsight Bias}

Fischhoff (1975) described the process he believed was responsible for hindsight bias as "creeping determinism." According to Fischhoff, "Upon receipt of outcome knowledge, judges immediately assimilate it with what they already know about the event in question. In other words, the retrospective judge attempts to make sense, or a coherent whole, out of all that he knows about the event" (1975, p. 297). Because the process was hypothesized to be quick and unconscious, Fischhoff described the outcome information as "creeping" into the subject's mental representation of the event resulting in cognitive restructuring. The characteristic effect of creeping determinism is the proclivity to view a known outcome as nearly inevitable, as revealed in retrospective probability judgments because of the seemingly unalterable sequence of events leading up to it (Hawkins \& Hastie, 1990). The "creeping determinism" hypothesis is consistent with more of the hindsight literature results than any other explanation offered (Hawkins \& Hastie, 1990).

Prior research reveals the presence of hindsight bias in several accounting settings. Financial statement users asked to assess a company's viability (Buchman, 1985) and jurors (Lowe \& Reckers, 1994) and judges (Anderson et al., 1995) asked to evaluate the actions of auditors have been found to be prone to hindsight bias. Brown and Solomon $(1987,1992)$ found that capital-budgeting decisions are influenced by outcome information, 
and Lipe (1993) found that managerial decisions involving variance investigations are affected by outcomes. In an auditing study involving internal control evaluations and audit opinion decisions, Reimers and Butler (1992) found that auditors exhibit significant (insignificant) hindsight bias when provided with surprising (unsurprising) outcome information. Both experienced and inexperienced auditors have been found to be prone to hindsight bias when making going-concern judgments (Kennedy, 1995; Anderson, 2000) and Kennedy (1995) found that outcomes influence auditors' analytical review judgments. These findings suggest that auditors are prone to hindsight bias which leads to the following baseline hypothesis:

H1: Despite instructions to ignore outcome information, auditors with outcome information will judge the reported outcome as more likely to occur than will auditors not provided with outcome information.

\section{Hindsight Bias and Cue Relevance Ratings}

Past psychological hindsight studies (Fischhoff, 1975; Wasserman et al., 1991) found that student subjects with outcome information (as compared to control subjects without outcome information) rated cues supporting the reported outcome as more relevant than the cues supporting non-reported outcomes. Fischhoff and Beyth (1975) explained the cue relevance ratings in terms of creeping determinism - in an attempt to make sense out of the reported outcome, cues supporting it become more salient, whereas cues supporting non-reported outcomes are deemphasized, reinterpreted, or forgotten.

The cue relevance findings can also be explained in terms of semantic memory network models. According to semantic memory network models (e.g., Collins \& Quillian, 1969; Collins \& Loftus, 1975; Smith, 1978), memory is organized in a hierarchical structure comprised of networks of nodes and the links among them. The nodes are grouped into subsets called schemata that represent prototypes of complex concepts or episodes (Thorndyke \& Hayes-Roth, 1979; Moeckel, 1990). When new information is encountered, memories representing possibly related concepts or episodes are accessed through a spreading of activation along the links among the nodes (Collins \& Loftus, 1975). These activated schemata control all processing of the new information, including not only its comprehension and encoding, but also its subsequent storage in memory (Moeckel, 1990; also see, e.g., Alba \& Hasher, 1983; Gibbins, 1984; Waller \& Felix, 1984).

The nodes within the network are linked closely with their related features and attributes. Due to spreading activation across the links among the network nodes, the case cues (i.e., the features and attributes) supporting the reported outcome will be easier to retrieve (i.e., are more available) than will the case cues supporting the non reported outcomes (e.g., see Meyer \& Schvaneveldt, 1976; Libby, 1985; Libby \& Frederick, 1990). As a result, cues supporting the reported outcome will be more available and therefore will be considered more salient and relevant. However, due to the differential costs of alternative audit decision errors, coupled with the unique nature of auditor training, auditors' cue relevance ratings are likely to differ from those of student subjects in a systematic way. This is discussed further in the next section.

\section{Differential Decision Error Costs}

A major difference between professional subjects and student subjects is that professionals' cognitive processing is affected by how familiar they are with the task. Professionals realize that there are costs associated with different decision errors, and these costs are asymmetric for some tasks. When auditors perform going-concern tasks, they make trade-offs between the cost of incorrectly predicting a company will succeed, when it in fact fails (e.g., risk of a lawsuit and damage to the firm's reputation), against the cost of incorrectly predicting a company will fail, when it in fact succeeds (e.g., risk of losing the client and its related audit fees).

Although the base-rate of actual company failures is rather low, the risk of a lawsuit is generally perceived to be far more costly than the risk of losing a client (e.g., Nelson, 1995). These differential costs have been offered as an explanation for the well-documented finding in the accounting literature that auditors are conservative when making going-concern decisions, weighting adverse factors more heavily than mitigating factors (e.g., Kida, 1984; Trotman \& Sng, 1989; Smith \& Kida, 1991; Asare, 1992). (These past studies, however, did not examine the effects of hindsight bias on auditors' ratings of adverse factors and mitigating factors.) 
Furthermore, auditors are trained, and are required by professional standards, to classify a company as one with going-concern problems only if, during normal auditing procedures, sufficient adverse factors have been identified to create "substantial doubt" about the company's ability to continue as a going concern. Only after sufficient adverse factors have been identified and evaluated does the auditor search for mitigating factors (Statement on Auditing Standards No. 59, AICPA, 1988). Auditors also realize that client management may be inclined to conceal adverse factors but has little incentive to conceal mitigating factors. This may train auditors to view adverse factors as more relevant. Also, based on theories of semantic memory network models, this training would cause the links to adverse factors to be stronger and more accessible than the links to mitigating factors.

As a result of the differential costs associated with failing to uncover adverse factors versus mitigating factors, coupled with the nature of auditor training, it is expected that auditors will rate adverse factors as more relevant than mitigating factors regardless of the outcome information provided. Any creeping determinism experienced by the auditors informed that the troubled company succeeded, thus causing them to view the mitigating factors as more relevant, is expected to be counteracted by their experience and training to view adverse factors as more relevant. However, it is expected that due to the presence of hindsight bias and the resulting creeping determinism, auditors informed that the troubled company failed will rate the adverse factors as more relevant than the mitigating factors, to a greater extent, than the auditors not provided with outcome information. This leads to the following two hypotheses:

H2: Regardless of the outcome information provided, auditors will rate cues supporting the failure outcome (i.e., adverse factors) as more relevant than cues supporting the success outcome (i.e., mitigating factors).

H3: Due to the effects of hindsight bias, auditors provided with the failure outcome will rate adverse factors as more relevant than the mitigating factors to a greater extent than will auditors not provided with outcome information.

\section{Effects of Experience}

Experienced auditors have more elaborate cognitive networks with more linkages and nodes than do inexperienced auditors. They will also have more training and work experience with client companies experiencing going-concern problems. As a result, they should be better able than inexperienced auditors to identify the adverse factors and to rate them as more relevant. This leads to the following hypothesis:

H4: Experienced auditors will exhibit greater cue relevance effects than will inexperienced auditors.

\section{METHOD}

\section{Subjects and Design}

Subjects consisted of 114 professional auditors employed by large international public accounting firms. Fifty-seven of the auditors were experienced with an average of 9.4 years of auditing experience and 57 were inexperienced with an average of 1.4 years of auditing experience. The overall average level of auditing experience was 6.2 years. They were randomly assigned to one of the three treatment conditions formed by a $2 \mathrm{X} 3$ (factor type by outcome type) design. The two levels of factor type were repeated measures, including adverse and mitigating factors. The three levels of outcome type were: no outcome (i.e., the foresight condition), failure outcome, and success outcome. There were two dependent variables in all conditions - the auditor's probability judgment that the case company would succeed within the next year (hereafter referred to as a viability judgment) and the auditor's relevance ratings for five adverse factors and five mitigating factors.

\section{Tasks}

Each subject received a packet of materials consisting of a sealed envelope, a page of general instructions, and the case data for a chemical manufacturer. The case data consisted of a narrative summary which contained an equal number of adverse factors and mitigating factors and three years of financial data, including the financial 
statements, a summary of financial highlights, and a set of financial ratios. After completing the case review task, the written instructions indicated that the subjects were to open the sealed envelope which contained the outcome information (if provided), the viability judgment task, the cue relevance rating task, and the debriefing task. The subjects were not allowed to use reference materials and were required to work independently.

The subjects' first task was to review the case data for a troubled chemical manufacturer. They were instructed to assume the role of supervisor on the year-end audit. They were also told that the fieldwork had been completed, but the final audit opinion had not yet been written. They were to review the company's financial statements in an attempt to assess viability. After reviewing the case data, subjects were instructed to begin the second task - the viability judgment. Before making their viability judgments, subjects in the failure outcome condition were informed that the company filed for bankruptcy during the last six months of the year subsequent to the year being audited. Subjects in the success outcome condition were informed that the company continued as a going concern throughout the year subsequent to the year being audited. Subjects in the no outcome condition were not provided with outcome information.

All subjects were instructed to assume that it was the last day of fieldwork for the year-end audit. At that time (when they would not have known what actually happened to the company), they were to estimate the likelihood that the company would or would not continue as a going concern throughout the year subsequent to the year being audited. The subjects in the failure outcome and success outcome conditions were instructed to ignore the outcome information. All of the subjects were informed that they could refer back to the case data if necessary before making their viability judgments.

Subjects were asked to assess the probability (existing at year-end) that the firm would continue as a going concern throughout the year subsequent to the year being audited. They did this by placing an " $\mathrm{X}$ " on a probability scale. Subjects were asked to express their judgment of the company's viability in terms of a probability between $0 \%$ and $100 \%$, where $0 \%$ indicates that the company is certain NOT to continue as a going concern and $100 \%$ indicates that the company is certain to continue as a going concern.

Following the viability judgment task, subjects were instructed to complete a cue relevance rating task. Subjects rated five adverse and five mitigating factors that were mentioned in the case data (see Table 1). They were instructed to indicate how relevant these factors were in reaching their viability judgments. They used a 7-point scale from 0 - no relevance at all - to 6 - extremely relevant. The final task for all subjects was completing a onepage debriefing questionnaire.

Table 1: Adverse Factors and Mitigating Factors Rated by Subjects

\author{
Adverse Factors \\ Management indicated that new legislation may make it difficult to market one of their major products. \\ Discussions with management indicate that a material liability from litigation is likely this year. \\ Management and labor representatives indicate that there is a chance that labor will strike this year. \\ Management indicates that there is a good chance of losing a major customer. \\ The company's current ratio is significantly below the industry average.

\section{Mitigating Factors} \\ The company's technology is competitive with other firms in the chemical industry. \\ The economic outlook for the chemical industry is stable. \\ In general, the company's suppliers indicate that usual trade credit to the company will be available. \\ Management states that it is possible that a key patent may be obtained in the near future. \\ The company's sales-to-assets ratio is near the industry average.
}

\title{
RESULTS
}

\section{Presence of Hindsight Bias}

H1 predicted that, despite instructions to ignore the outcome information, auditors with outcome information would judge the reported outcome as more likely to occur than would auditors not provided with 
outcome information. More specifically, auditors informed that the company failed (succeeded) would be more likely to judge the continued viability of the company as being less (more) likely than the auditors not provided with outcome information. The means and standard deviations for the viability judgment dependent variable are found in Table 2.

Table 2: Means and (Standard Deviations) of Viability Judgments by Experimental Conditions

\begin{tabular}{|l|c|c|}
\hline \multicolumn{2}{|c|}{ Outcome Type } \\
\hline No. & Failure & Success \\
\hline $60.66 \%$ & $54.37 \%$ & $67.00 \%$ \\
\hline$(17.24)$ & $(17.06)$ & $(17.80)$ \\
\hline $\mathrm{n}=38$ & $\mathrm{n}=38$ & $\mathrm{n}=38$ \\
\hline
\end{tabular}

In order to test $\mathrm{H} 1$, it was necessary to determine if the failure outcome mean viability judgment of $54.37 \%$ and the success outcome mean viability judgment of $67 \%$ are significantly different from the no outcome mean viability judgment of $60.66 \%$. The failure outcome subjects' mean viability judgment of $54.37 \%$ is significantly less than the no outcome subjects' mean viability judgment of $60.66 \%$ ( $\mathrm{p}=0.06$, one-tailed probability). This indicates that, despite instructions to ignore the outcome information, being informed that the company failed caused the subjects in the failure outcome condition to judge continued viability as less likely than did the no outcome subjects. In other words, the failure outcome subjects were prone to hindsight bias.

In addition, the success outcome subjects' mean viability judgment of $67.00 \%$ is significantly greater than the no outcome subjects' mean viability judgment of $60.66 \%(\mathrm{p}=0.059$, one-tailed probability). This indicates that, despite instructions to ignore the outcome information, being informed that the company succeeded caused the subjects in the success outcome condition to judge continued viability as more likely than did the no outcome subjects. In short, both the failure outcome and the success outcome subjects were prone to hindsight bias. This provides support for HI; auditors with outcome information judged the reported outcome as more likely to occur than did auditors not provided with outcome information.

\section{Cue Relevance}

$\mathrm{H} 2$ predicted that regardless of the outcome information provided, auditors would rate adverse factors as more relevant than mitigating factors. The means and standard deviations for the cue relevance dependent variable are presented in Table 3. To test $\mathrm{H} 2$, a $2 \mathrm{X} 3$ (factor type by outcome type) ANOVA was performed. The factor type is a repeated measures design with two levels (adverse factors and mitigating factors) and the outcome type is between subjects with three levels (no outcome, failure outcome, and success outcome). The ANOVA results are presented in Table 4.

The Factor Type by Outcome interaction was not significant $(\mathrm{p}=0.169)$. Contrary to the findings in the psychological literature, the failure outcome subjects did not rate the adverse factors as more relevant than did the no outcome subjects and, likewise, the success outcome subjects did not rate the mitigating factors as more relevant than did the no outcome subjects. The factor type variable, however, was significant $(\mathrm{p}=0.000)$, indicating that the mean cue relevance rating for adverse factors was significantly greater than the mean cue relevance rating for mitigating factors in all three outcome groups. Therefore, $\mathrm{H} 2$ is supported.

Table 3: Means and (Standard Deviations) of Cue Relevance Ratings by Experimental Conditions

\begin{tabular}{|l|c|c|c|}
\hline \multirow{2}{*}{ Factor Type } & \multicolumn{2}{|c|}{ Outcome Type } & Success \\
\cline { 2 - 4 } & No & Failure & 4.28 \\
Adverse & 4.30 & 4.44 & $(.81)$ \\
& $(.88)$ & $(.86)$ & $\mathrm{n}=38$ \\
\hline \multirow{3}{*}{ Mitigating } & $\mathrm{n}=38$ & $\mathrm{n}=38$ & 3.63 \\
& 3.67 & 3.39 & $(.67)$ \\
\end{tabular}


$\mathrm{H} 3$ predicted that, due to the effects of hindsight bias, auditors provided with the failure outcome would rate the adverse factors as more relevant than would auditors not provided with outcome information. To test this, it was necessary to determine if the difference between the mean cue relevance rating for the adverse factors and the mean cue relevance rating for the mitigating factors was significantly different between the no outcome and failure outcome groups.

The difference between the mean cue relevance rating for the adverse factors (AFs) and the mean cue relevance rating for the mitigating factors (MFs) for the no outcome (NO) and failure outcome (FO) groups are as follows: $\mathrm{NO} / \mathrm{AFs}=4.30 ; \mathrm{NO} / \mathrm{MFs}=3.67 ; \mathrm{FO} / \mathrm{AFs}=4.44 ; \mathrm{FO} / \mathrm{MFs}=3.39$. This indicates that the failure outcome subjects, using a 7-point scale, rated the adverse factors an average of 1.05 more relevant than they rated the mitigating factors $(4.44-3.39=1.05)$. The no outcome subjects rated the adverse factors an average of .63 more relevant than they rated the mitigating factors $(4.30-3.67=.63)$.

To determine the extent to which the failure outcome difference of 1.05 is greater than the no outcome difference of .63, the Factor Type by Outcome interaction sum of squares (presented in Table 4) was subdivided and subjected to further analysis.

Table 4: ANOVA: Factor Type by Outcome Type on Cue Relevance Ratings

\begin{tabular}{|l|c|c|c|c|c|}
\hline \multicolumn{1}{|c|}{ Source of Variation } & SS & DF & MS & F & Sig.of F \\
\hline Factor Type & 856.86 & 1 & 856.86 & 58.12 & .000 \\
\hline Factor Type by Outcome & 52.85 & 2 & 26.43 & .79 & .169 \\
\hline
\end{tabular}

According to this analysis (presented in Table 5), the 1.05 failure outcome difference is significantly greater than the .63 no outcome difference ( $\mathrm{p}=0.047$, one-tail probability). Thus, $\mathrm{H} 3$ is supported.

Table 5: ANOVA: Factor Type by Outcome Type (No Outcome versus Failure Outcome) on Cue Relevance Ratings

\begin{tabular}{|l|c|c|c|c|c|}
\hline \multicolumn{1}{|c|}{ Source of Variation } & SS & DF & MS & F & Sig. of F \\
\hline Factor Type by Outcome & 52.85 & 2 & 26.43 & 1.79 & .169 \\
\hline Factor Type by (No Outcome vs. Failure Outcome) & 42.11 & 1 & 42.11 & 2.86 & .094 \\
\hline
\end{tabular}

\section{Effects of Experience}

H4 predicted that experienced auditors would exhibit greater cue relevance effects than would inexperienced auditors. A 2 X2X3 repeated measures ANOVA (experience by factor type by outcome) revealed that the experience by factor type interaction is not significant ( $p=0.193)$; therefore, H4 is not supported.

\section{DISCUSSION \& CONCLUSION}

The purpose of this study was to examine the effects of hindsight bias on auditor judgment and the degree to which the bias influences cue relevance ratings. Consistent with prior auditing research, the current study found that auditors are prone to hindsight bias when making probability judgments (HI). Contrary to the psychological literature, the current study predicted and found that, due to the unique nature of auditor training and expertise, auditors rate adverse factors as more relevant than mitigating factors regardless of the outcome information provided (H2). The current study also predicted and found that due to the presence of hindsight bias, auditors with failure outcome information rate adverse factor as more relevant than mitigating factors to a greater extent than do auditors not provided with outcome information (H3). The current study did not find that experienced auditors exhibited greater cue relevance effects as compared to inexperienced auditors ( $\mathrm{H} 4)$.

The presence of hindsight bias in the context of going-concern judgments and its effects on cue relevance ratings presents several important implications for the auditing profession. First, the "knew-it-all-along" attitude created by hindsight bias may impede feedback learning (Fischhoff, 1975), thereby reducing what auditors could potentially learn from the feedback provided by actual bankruptcies. The presence of hindsight bias is particularly troubling in the case of the failure outcome. As compared to success outcomes, auditors have limited actual experience with failure outcomes. Also, because inaccurately predicting the failure outcome (i.e., issuing an 
unqualified opinion to a troubled company that subsequently fails) poses more dire consequences for public accounting firms than does inaccurately predicting the success outcome (i.e., issuing a modified opinion to a troubled company that continues), it is imperative that auditors learn as much as they can from troubled companies that fail. A second important implication of the presence of hindsight bias in a going-concern context is that auditors who issue unqualified opinions to client companies that subsequently fail may be unfairly evaluated, in hindsight, by interested third parties such as the SEC, stockholders, expert witnesses, jurors, and peers (Kennedy, 1995; Lowe \& Reckers, 1994). These third parties may be unable to ignore the outcome information they have (i.e., the company did indeed fail) that the auditors did not have at the time they made their opinion decision.

Third, if the presence of hindsight bias caused auditors to rate cues supporting the reported outcome as more relevant, which is consistent with the findings in the psychological literature, then auditors informed that a troubled company continued would rate the mitigating factors as more relevant than the adverse factors. Given that auditors have far more actual experience with the success outcome, this would indicate that, over time, auditors would come to view mitigating factors as more relevant than adverse factors. This could cause auditors to devalue the importance of adverse factors, which could lead to issuing unqualified audit opinions to companies that subsequently fail. Viewing mitigating factors as more relevant also violates professional standards, which require auditors to first identify whether or not there are sufficient adverse factors to create "substantial doubt" about a company's ability to continue as a going concern and then to search for any mitigating factors (Statement on Auditing Standards No. 59, AICPA, 1988).

However, the current study predicted and found that due to the unique nature of their training and expertise, the influence of hindsight bias on cue relevance effects in an audit setting systematically differ from those found in psychological studies using student subjects and simplified tasks. Professional auditors realize that there are differential decision error costs associated with some tasks. The error of incorrectly issuing an unqualified audit opinion to a company that subsequently fails is extremely costly in terms of the risk of a lawsuit and the resulting damage to the public accounting firm's reputation. The error of incorrectly issuing a modified opinion to a company that subsequently continues is generally perceived to be far less costly, resulting in at most the loss of the client and its related audit fees. This asymmetry in decision error costs causes auditors to view adverse factors as far more relevant than mitigating factors in the context of going-concern judgments. In addition, auditors are required by professional standards and are trained to view adverse factors as more relevant than mitigating factors. The current study's finding that auditors do in fact rate adverse factors as more relevant than mitigating factors, despite the outcome information provided, illustrates a unique case where the presence of hindsight bias does not lead to the over weighting of confirming evidence as found in the psychological literature. It also illustrates the success of auditor training programs, which attempt to train auditors to regard adverse factors as more relevant than mitigating factors in compliance with professional standards and in reaction to the differential decision error costs associated with going-concern decisions. In short, researchers need to exercise caution when importing results from the psychological literature using student subjects and generic tasks to an auditing domain using professional auditors performing specialized tasks.

\section{AUTHOR INFORMATION}

Kim L. Anderson, Ph.D., is an Associate Professor in the Department of Accounting at Indiana University of Pennsylvania. Her research interests lie in the areas of behavioral auditing research and financial accounting. Her previous work has appeared in the Pennsylvania Journal of Business \& Economics, and she currently has a paper under review at Contemporary Accounting Research. E-mail: Kim.Anderson@iup.edu

\section{REFERENCES}

1. $\quad$ Alba, J. W., \& Hasher, L. (1983). Is memory schematic? Psychological Bulletin, 203-231.

2. American Institute of Certified Public Accountants, Statement on Auditing Standards No. 59. (1988). The auditor's consideration of an entity's ability to continue as a going concern. New York, NY: AICPA.

3. American Institute of Certified Public Accountants, Statement on Auditing Standards No. 64. (1990). Omnibus statement on auditing standards -- 1990: The auditor's consideration of an entity's ability to continue as a going concern. New York, NY: AICPA. 
4. Anderson, J. C., Jennings, M. M., Kaplan, S. E., \& Reckers, P. M. J. (1995). The effect of using diagnostic decision aids for analytical procedures on judges' liability judgments. Journal of Accounting and Public Policy, 33-62.

5. Anderson, K. L. (2000, Spring). Hindsight bias and auditors' going-concern judgments: The effects of experience. Pennsylvania Journal of Business \& Economics.

6. Asare, S. (1992). The auditor's going concern decision: Interaction of task variables and the sequential processing of evidence. The Accounting Review, 379-393.

7. Brown, C. E., \& Solomon, I. (1987, July). Effects of outcome information on evaluations of managerial decisions. The Accounting Review, 564-577.

8. Brown, C. E., \& Solomon, I. (1992). An experimental investigation of explanations for outcome effects on appraisals of capital-budgeting decisions. (Working Paper). University of Illinois at Urbana-Champaign.

9. Buchman, T. A. (1985, July). An effect of hindsight on predicting bankruptcy with accounting information. Accounting, Organizations, and Society, 267-285.

10. Collins, A. M., \& Loftus, E. F. (1975). A spreading-activation theory of semantic processing. Psychological Review, 407-428.

11. Collins, A. M., \& Quillian, M. R. (1969). Retrieval time from semantic memory. Journal of Verbal Learning and Verbal Behavior, 240-248.

12. Davies, M. (1987, August). Reduction of hindsight bias by restoration of foresight perspective: Effectiveness of foresight-encoding and hindsight-retrievability strategies. Organizational Behavior and Human Decision Processes, 50-68.

13. Fischhoff, B. (1975, August). Hindsight = foresight: The effect of outcome knowledge on judgment under uncertainty. Journal of Experimental Psychology: Human Perception and Performance, 288-299.

14. Fischhoff, B., \& Beyth, R. (1975, February). I knew it would happen - Remembered probabilities of oncefuture things. Organizational Behavior and Human Performance, 1-16.

15. Gibbins, M. (1984). Propositions about the psychology of professional judgment in public accounting. Journal of Accounting Research, 103-125.

16. Hawkins, S. A., \& Hastie, R. (1990, May). Hindsight: Biased judgments of past events after the outcomes are known. Psychological Bulletin, 311-327.

17. Kennedy, J. (1995, April). Debiasing the curse of knowledge in audit judgment. The Accounting Review, 249-273.

18. Kida, T. E. (1984, Spring). The impact of hypothesis-testing strategies on auditors' use of judgment data. Journal of Accounting Research, 332-340.

19. Libby, R. (1985). Availability and the generation of hypotheses in analytical review. Journal of Accounting Research, 648-667.

20. Libby, R., \& Frederick, D. M. (1990). Experience and the ability to explain audit findings. Journal of Accounting Research, 348-367.

21. Lipe, M. G. (1993). Analyzing the variance investigation decision: The effects of outcome, mental accounting, and framing. (Working Paper). University of Michigan.

22. Loftus, E. F., \& Loftus, G. R. (1980). On the permanence of stored information in the human brain. American Psychologist, 409-420.

23. Lowe, D. J., \& Reckers, P. M. J. (1994, May). The effects of hindsight bias on jurors' evaluations of auditor decisions. Decision Sciences, 401-426.

24. Maddocks, P. M. (1989). Outcome knowledge and auditor judgment. (Unpublished doctoral dissertation). University of Florida.

25. Mazursky, D., \& Ofir, C. (1990). I could never have expected it to happen: The reversal of the hindsight bias. Organizational Behavior and Human Decision Processes, 20-33.

26. McDaniel, L. S., \& Kinney, W. R., Jr. (1994). Expectation-formation guidance in the auditor's review of interim financial information. Journal of Accounting Research, 275-291.

27. Meyer, D. E., \& Schvaneveldt, R. W. (1976). Meaning, memory, structure and mental processes. In C. N. Cofer (Ed.), The structure of human memory. San Francisco, CA: W. H. Freeman and Co.

28. Moeckel, C. (1990). The effect of experience on auditors' memory errors. Journal of Accounting Research, 368-387.

29. Nelson, M. K. (1995). Strategies of auditors: Evaluation of sample results. Auditing: A Journal of Practice and Theory, 34-49. 
30. Reimers, J. L., \& Butler, S. A. (1992, February). The effect of outcome knowledge on auditors' judgmental evaluations. Accounting, Organizations, and Society, 185-194.

31. Smith, E. E. (1978). Theories of semantic memory. In W. K. Estes (Ed.), Handbook of learning cognitive processes. Hillsdale, NJ: Erlbaum Press.

32. Smith, J. F., \& Kida, T. (1991). Heuristics and biases: Expertise and task realism in auditing. Psychological Bulletin, 472-489.

33. Thorndyke, P., \& Hayes-Roth, B. (1979). The use of schemata in the acquisition and transfer of knowledge. Cognitive Psychology, 82-106.

34. Trotman, K., \& Sng, J. (1989). The effect of hypothesis framing, prior expectations, and cue diagnosticity on auditor's information choice. Accounting, Organizations, and Society, 565-576.

35. Tversky, A., \& Kahneman, D. (1974). Judgment under uncertainty: Heuristics and biases. Science, 11241131.

36. Waller, W., \& Felix, W. (1984). Cognition and the auditor's opinion formulation process. In S. Moriarity \& E. Joyce (Eds.), Decision making and accounting: Current research (pp. 27-48). Norman, OK: University of Oklahoma.

37. Wasserman, D., Lempert, R. O., \& Hastie, R. (1991). Hindsight causality. Personality and Social Psychology Bulletin, 30-35. 